\title{
MACROBENTHIC COMMUNITY STRUCTURE DURING FALLOW SEASON IN KOLE PADDY FIELDS, NORTHERN KERALA, INDIA
}

\author{
Vineetha $S^{*}$ \\ *Department of Marine Biology, Microbiology \& Biochemistry, School of Marine Sciences, Cochin University of \\ Science and Technology, Fine Arts Avenue, Kochi-682016, Kerala
}

\section{*Corresponding Author: -}

\begin{abstract}
: -
Despite the recognized contribution of benthic fauna in nutrient enhancement, very little information is available from Indian paddy fields. This study analyzed the benthic community structure during fallow season in Kole paddy fields, a part of Vembanad Kole wetlands (a Ramsar site), Northern Kerala, India. Study area during fallow season was characterized by isolated water patches amidst of terrestrial vegetation (grass). The macrobenthic fauna belonged to the phyla Annelida, Arthropoda, Mollusca and families Tubificidae, Naididae, Chironomidae, Ceratopogonida, Chaoboridae, Ceratopogonidae, Gyrinidae and Bithynidae. These organisms possessed various survival mechanisms that ensured their survival against dry periods. Insects were the major benthic organisms; the habitat fragmentation due to isolated distant water patches during fallow season favored insect taxa more due to their activelflight mode of dispersal compared to oligochaetes which are benthic crawlers. Macrobenthic abundance was less $\left(166 \pm 60 \mathrm{ind} . / \mathrm{m}^{2}\right)$, attributed to reduced habitable area for benthos due to habitat desiccation. A decline in abundance was apparent from January to June 2010, the beginning to end of fallow season except in April where the onset of rain after a dry spell made the dry area wet, thereby making the inactive dormant forms of organisms live, resulting in an increased abundance. Diversity analysis of benthic families revealed that highest richness $(d)$ of 1.235 was in March and diversity $\left(H^{\prime}\right)$ of 2.603 was in March. No significant correlation emerged between benthic abundance and the measured environmental parameters, implying that the interaction of biota and physico chemical variables was overridden by some other unmeasured factors.
\end{abstract}

Keywords: - Benthic fauna. Fallow phase. Paddy fields. Vembanad Kole wetland

\section{(a) $(\$)$}




\section{INTRODUCTION}

Rice is the staple food for at least 33 countries and its cultivation perhaps dates back long before the era for which there is historical evidence (Fernando 1977). Paddy fields are considered as temporary wetlands due to the presence of standing water body which is temporary and seasonal. Though paddy fields seems to be monoculture agroecosystems, on a temporal scale it undergoes three major ecological phases such as aquatic, semi aquatic, terrestrial or dry within a paddy cultivation cycle (Fernando 1995). The hydrological and sedimental conditions get altered due to this, eventually affecting the inhabitant biota. For aquatic organisms, as the phase shift to terrestrial dry phase, the entire habitat shifts from being available to unavailable, resulting in its habitat loss and habitat fragmentation. Benthic fauna, the organisms that live, on or in the bottom of the water body form an important component of aquatic ecosystems. Besides its role in food chain, they are crucial components for paddy field fertility due to its key role in nutrient translocation and organic matter decomposition (Roger et al., 1987). They can liberate dissolved nutrients by their feeding activities, excretion and burrowing into sediments and enhance the rate of decomposition of particulate matter (Covich et al., 1999; Stripari and Henry, 2002).The native fertility of paddy fields depends on replenishment of soil nutrients, determined largely by these organisms. However as aquatic biota, are characterized by adaptations to an existence in water, drying during fallow seasons in paddy fields could stress or even eliminate these biota. This study analyzed the composition, abundance and community structure of benthic fauna present in the paddy fields during the fallow season. The study area Kole paddy fields, a part of Vembanad kole wetlands, a Ramsar site are among the water-logged, paddy cultivating areas in Kerala, India. Kole wetlands were under rice cultivation for the past 200 years since the erstwhile Maharaja permitted to convert this wetland into paddy fields in the early 18th century (Anon., 1989). They are renowned for its high rice production, even the term Kole in Malayalam (the regional language in Kerala) means 'bumper yield of high returns in case flood does not damage the crops' (Johnkutty and Venugopal, 1993). Moreover this wetland comes under Central Asian- Indian flyway of migratory birds where water birds halt for short periods to rest and feed during their annual migrations, and these 'stepping stones' are essential for their survival (Anon, 1996; Sivaperuman and Jayson, 2000). The role of benthic invertebrates as food for avian fauna also emphasizes the need for benthic study.

\section{Materials and Methods \\ Study area}

The Kole lands are saucer shaped tracts, lying 0.5 to $1.5 \mathrm{~m}$ below the mean sea level, covering an area of 13,632 ha. spreading over Thrissur and Malappuram districts. The Viyyam dam is situated at the downstream end of Kole lands which prevents the intrusion of salt water to the Kole lands. The Kole lands are believed to be lagoons formed by the recession of seas centuries back. A shallow portion of the sea along the western periphery of the main land was isolated and they were gradually silted up during rains making the lagoons shallow. The farmers then bunded the fields, dewatered and raised rice in summer months. During the rains, the inflow into the basin submerges all the kole areas. The area normally remains flooded from June to January. The main crop is Punja (summer crop) raised during January to April. Towards the close of the North East monsoon, water from the rice fields are pumped out and sowing or transplanting is done by January. The kole lands are dewatered after protecting the rice fields (Padavu or Padashekharam) with permanent or temporary earthen bunds (Mattoms). Dewatering is done by an indigenous axial flow centrifugal pumping device ( $p e t t i$ and para).

The study area, with an area of 100 acres, lies in between Maranchery and Veliyamkodu panchayaths in Malappuram district and is a part of the Ponnani Kole. Five stations that were under seasonal paddy cultivation were selected for monthly sampling (Fig.1). In January 2010, water was drained as the preparation for paddy cultivation but due to the accidental breaching of an adjacent earthen bund, these sites were again filled with water in February. Due to this the paddy fields were left fallow without cultivation so the land was covered with grass where cattle pastured, resembling a terrestrial ecosystem. Sampling for macrobenthic fauna and sediment parameters were done from isolated water patches. The sampling areas were just muddy enough to collect benthic samples so water could not be sampled.

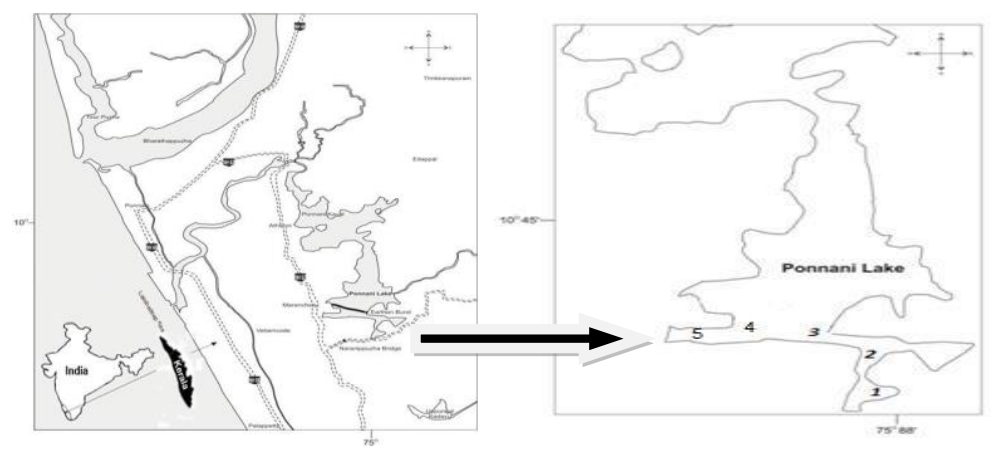

Figure.1. Location of sampling stations in Maranchery Kole paddy fields 


\section{Sampling and Analysis}

Five sampling stations were chosen and the field sampling was carried out during the fallow season January to May 2010 on a monthly basis for the study of macrobenthos and environmental parameters. February 2010 was excluded as the sampling stations were inundated due to bund breach. Sediment samples for the analysis were collected using a Van Veen grab of size $0.45 \mathrm{~m}^{2}$. Temperature was measured in the field using a standard degree centigrade thermometer of $0^{\circ} \mathrm{C}$ to $50^{\circ} \mathrm{C}$ range and $0.1^{\circ} \mathrm{C}$ accuracy. $\mathrm{pH}$ was measured using Systronics digital $\mathrm{pH}$ meter model MK VI. Organic carbon was determined by Walkley - Black method, then converted to organic matter by multiplying with Van Bemmelen factor of 1.742 (Jackson, 1973). Available nitrogen of sediment was analyzed by Kjeldhal method (Jackson, 1973; Carter, 1993). Available phosphorus was determined by Olsen's method (Olsen et al., 1954). Particle size was analyzed using particle analyzer Sympatrec T 100 laser diffraction granulometer, made in Germany. Rain fall data was collected from the Indian Meteorological Department website (imd.gov.in). Sediment samples in replicate were collected for the analysis of macrobenthos using a VanVeen grab of size $0.45 \mathrm{~m}^{2}$. The samples were washed in the field itself through a sieve of mesh size $500 \mu \mathrm{m}$ and those that were retained in the sieve were collected and preserved in 5\% formalin (Holme and McIntyre, 1971; McIntyre and Eleftheriou, 2005). The organisms were sorted into different taxonomic groups. Identification was done using standard keys (Yule and Sen, 2004; Morse et al., 1994).

PRIMER 6 (Plymouth Routines in Multivariate Ecological Research, version 6) was used to analyze diversity indices of macrobenthic families such as species richness by Margalef's index (Margalef, 1958), species diversity by Shannon index (Shannon Wiener, 1949) (Pielou, 1966) and species dominance by Simpson's index (Simpson, 1949). The software programme SPSS 16 (Statistical Programme for Social Sciences, version 16) was used for correlation analysis to find the relationship between environmental parameters and benthic abundance.

\section{Results and Discussions}

The environmental parameters during fallow season were as follows. The average value of rainfall was $173.6 \pm 250.17 \mathrm{~mm}$. After a dry spell, in April there was intermittent rainfall $(92.7 \mathrm{~mm})$, which continued intermittently till the end of fallow season. Depth of the water patches was $0.36 \pm 0.14 \mathrm{~m}$. Sediment temperature was $27.66 \pm 3.35^{\circ} \mathrm{C}$, fallow season existed in summer months, so the higher temperature is as expected. Sediment $\mathrm{pH}$ was neutral showing an average value of $6.45 \pm 0.44$. Organic matter was $3.88 \pm 1.85 \%$. The reduced water level could have concentrated the organic matter resulting in a higher organic matter level as observed by

Lobinske et al. (1996) and Real et al. (2000). However the values were comparable to previous studies; Hameed (1975) reported that in Kole wetlands, the organic carbon content of the soil was high ranging from 2.07-4.16\% and In Muriyad wetland, a part of Kole wetlands, the range was 0.21 to $1.11 \%$ (Thomas et al. 2003). Moisture content was $29.73 \pm 8.36 \%$, high organic matter improves water holding capacity of sediments

(Reddy and Delaune 2008). Available nitrogen and available phosphorus were $0.021( \pm 0.006) \%$ and $1.07( \pm 0.76) \mathrm{ppm}$ respectively. Sediment texture was silty clay in nature.

The macrobenthic fauna during fallow season in Maranchery paddy fields belonged to the phyla Annelida (24.07\%), Arthropoda (74.86\%), Mollusca (1.07\%) and classes Oligochaeta, Insecta, Gastropoda. Oligochaets were represented by families Tubificidae (34\%) and Naididae (24\%). Insects were represented by Diptera [Chironomidae (26\%), Ceratopogonida (6\%), Chaoboridae (2\%)]; Trichoptera [(Gyrinidae (4\%), Hydrophilidae (3\%)]; Gastropoda represented by Bithynidae (1\%) (Fig.2). As fallow season was characterized by the absence of water, the survival of benthos being aquatic organisms might be at threat. Fauna surviving in this conditions require adaptations include physiological, behavioral, morphological and life history strategies (Humphries and Baldwin 2003). The following organisms which were present in Maranchery Kole wetlands were capable of surviving in dry conditions by specific mechanisms such as in Oligochaeta by diapausing eggs; resistant cysts enclosing young, adults or fragments of individuals; that in Diptera: Chironomidae (insecta) by diapausing eggs, resistant late instar larvae, sometimes in cocoons of silk or mucus; that in Trichoptera (insecta) by diapausing eggs, resistant gelatinous egg mass, terrestrial pupae in some species, recolonising adults, larvae deep in substrate; that in Gastropoda by adults forming a protective epiphragm of dried mucus across shell opening, adults and young survive in moist air/soil under algal mats on pond/stream bed. So the benthic organisms which were present during the fallow season were found to have some survival mechanisms against dry periods. Insects were the most numerically abundant group during this season. The major benthic organism were insects, the habitat fragmentation due to isolated distant water patches during fallow season favored insect taxa more due to their active/flight mode of dispersal compared to oligochaetes which are benthic crawlers. Previous studies on temporary environments across the world also reported that the aquatic insects were the major component of the fauna in these types of habitats (Lake et al. 1989, Bazzanti et al. 1996, Boix et al. 2001).

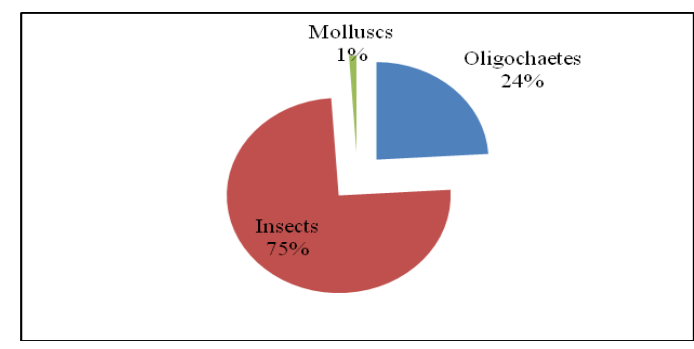

Figure.2. Mean percentage composition of macrobenthic faunal groups during fallow phase 
The average macrobenthic abundance was $166 \pm 60$ ind. $/ \mathrm{m}^{2}$, the abundance of oligochaetes was $40 \pm 53$ ind. $/ \mathrm{m}^{2}$ and that of insects was $124 \pm 168 \mathrm{ind} . / \mathrm{m}^{2}$. The monthly abundance pattern showed a declining trend from January $\left(328 \mathrm{ind} . / \mathrm{m}^{2}\right)$ to June $\left(76 \mathrm{ind} . / \mathrm{m}^{2}\right)$, the beginning and end of fallow season respectively except an increase in April $2010\left(178 \mathrm{ind} . / \mathrm{m}^{2}\right)$ (Fig.3). While comparing the macrobenthic abundance in fallow season to that of its paddy cultivating season (JanuaryMay 2011), a higher macrobenthic abundance of $399 \pm 581$ ind.$/ \mathrm{m}^{2}$ was observed during paddy growing season (Vineetha et al. 2015). In paddy cultivating season, the area remains inundated, when the area under inundation is increased, the habitable area increase and the number of organisms increase obviously (Sommer and Horwitz 2009). Most of the previous studies also documented an increase in benthic abundance with higher water levels (Cantrell 1988, Gascon et al. 2007). During fallow season, due to habitat desiccation, wet area or habitable area for benthos was restricted to few isolated water patches. This resulted in concentrating the benthic organisms to the available water patches which serve as the only habitable areas for benthic organisms. Due to this limited habitable area greater competition and other abundancedependent effects results which lead to a reduced numerical abundance in fallow season as observed by Aspbury and Juliano (1998). Furthermore due to shallow nature of the water body, birds and other invertebrates can access the water patches easily thus the threat of predation from birds and other invertebrates are more which can reduce the abundance. Another peculiarity in the dry phase is that flocks of ducks were allowed to feed in the area during this period which also would have resulted in a reduced abundance. These findings are in agreement with the observations of Sommer and Horwitz (2009) who opined that drying wetlands concentrate aquatic prey for wading birds that utilize the wetland for feeding thus resulting in less numerical abundance of benthic organisms. An increase in abundance in April 2010 was noticed during this study. A medium rainfall in April 2010, after a dry spell made the dry area wet, thereby making the inactive dormant forms of organisms live, which would have contributed an increase in abundance in April 2010. Though there was an increase in rainfall since April 2010, a prominent increase in abundance was not obvious.

The rain after the dry spell would have made the difference rather than a continuous rainfall.

Diversity analysis of benthic families revealed that richness (d) ranged from 0.6091 in January to 1.235 in March; Evenness $\left(J^{\prime}\right)$ ranged from 0.6934 in May to 0.9273 in March, Diversity $\left(\mathrm{H}^{\prime}\right)$ ranged from 1.141 in

January to 2.603 in March and Dominance $(\lambda$ ') ranged from 0.1755 in March to 0.4906 in January (Fig.4 ). Even though January, the beginning of fallow season showed the highest benthic abundance, richness and diversity of benthic families were lowest there whereas in March, all the benthic families were present except Bithynidae which resulted in the highest richness and diversity of macrobenthic families in March 2010.

While analyzing the interactions among macrobenthic abundance and environmental parameters, no significant correlation emerged between them, the maximum correlation was observed between sediment temperature and numerical abundance of macrobenthos $\left(r^{2}=-0.35, p=0.51\right)$. The absence of significant correlation could be due to the marked generalist character of oligochaetes and chironomids, the most abundant taxa in fallow phase whose distribution showed random patterns in previous studies (Thorp and Couch, 2001, McLachlan 1985). Due to the restricted availability of habitable space, in spite of the physico chemical parameters, other factors including life history strategy (Wiggins et al., 1980, Williams, 1996) would have played a major role overriding the relationship with measured parameters.

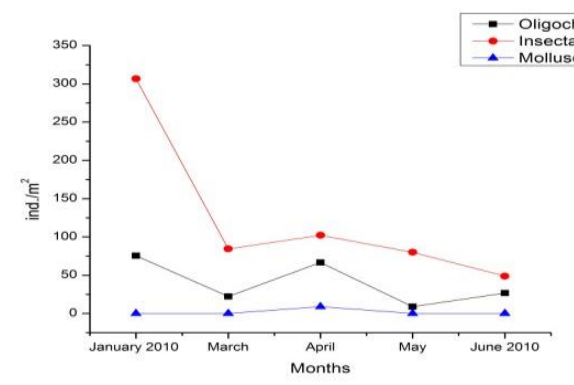

Figure.3. Monthly variation in numerical abundance of macrobenthic fauna

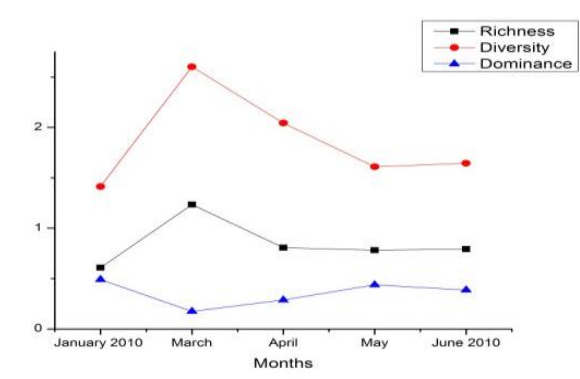

Figure.4. Monthly variation in diversity indices of macrobenthic families

Up to $50 \%$ of the globe's agricultural land and $60 \%$ of ecosystem services are now affected by some degree of degradation, with agricultural land use, the chief cause of land degradation (MEA 2005). Of late agricultural production systems are focusing more on the effective conservation and management of biodiversity and ecosystem services to address the twin objectives of food security and environmental sustainability. Despite the recognized role of benthic fauna in nutrient enrichment of paddy fields, the information on benthic fauna from Indian paddy fields remains scantly though India stands first in area under rice cultivation, second in rice production and has an agricultural based economy (Balachandran, 2007). The sustainable utilization of agricultural biodiversity is likely to be particularly beneficial for small-scale farmers, who need to optimize the available limited resources.

\section{Acknowledgements}

The author is thankful to the Head of the Department of Marine biology, Microbiology and Biochemistry, Cochin university of Science and Technology for providing necessary facilities. The author is thankful to University Grants Commission for the research fellowship. This study was a part of the research project funded by Kerala state Biodiversity Board, the author is thankful to them. 


\section{References}

[1].Anonymous, 1996. Asia-Pacific Water bird Conservation Strategy, 1996-2000. Wetlands International AsiaPacific, Kula Lumpur, Publication No.117, and International Waterfowl and Wetlands Research Bureau - Japan Committee, Tokyo

[2].Anonymous. 1989. Scheme for studying the possible changes in the ecosystem consequent on the conservation of Thannermukkam Bund, Thrissur, Kerala. Kerala Agricultural University.

[3].Aspbury AS, Juliano SA. 1998. Negative effects of habitat drying and prior exploitation on the detritus resource in an ephemeral aquatic habitat. Oecologia 115(1-2):137-148.

[4].Balachandran, P.V. 2007. Rice scenario of Kerala and the future strategies. Proceedings of XIX Kerala Science Congress, Kannur, Kerala 22-32 pp.

[5].Bazzanti M, Della Bella V, Seminara M, 2003. Factors affecting macroinvertebrate communities in astIatic ponds in central Italy. Journal of Freshwater Ecology 18:537-548.

[6].Boix D, Sala J, Quintana XD, Moreno-Amich R. 2004. Succession of the animal community in a Mediterranean temporary pond. Journal of the North American Benthological Society 23:29-49.

[7].Boulton AJ. 1989. Over-summering refuges of aquatic macroinvertebrates in two intermittent streams in Victoria. Transactions of the Royal Society of South Australia. 113:23-34.

[8].Cantrell MA. 1988. Effect of lake level fluctuations on the habitats of benthic invertebrates in a shallow tropical lake. Hydrobiologia 158:125-131.

[9].Carter, M. R., Parton,W. J., Rowland, I. C., Schultz, J. E., and Steed, G. R. 1993. Simulation of soil organic carbon and nitrogen changes in cereal and pasture systems of southern Australia, Austr. J. Soil Res., 31, 481- 491.

[10]. Covinch, A.P., Palmer, M.A. and Crowl, T.A. 1999. The role of benthic invertebrate species in freshwater ecosystems. BioScience. vol. 49( 2):119-127

[11]. Fernando C H. 1995. Rice fields are aquatic, semi aquatic, terrestrial and aqua cultural: A complex and questionable limnology. In tropical Limnology Eds. K H Timotius and F Goltenboth 1:121-148.

[12]. Fernando, C. H. 1977. Investigations on the aquatic fauna of tropical rice fields with special reference to South East Asia. GEO-ECO-TROP 3: 169-188.

[13]. Gascon S, Brucet S, Sala J, Boix D, Quintana XD. 2007. Comparison of the effects of hydrological disturbance events on benthos and plankton salt marsh communities. Estuarine, Coastal and Shelf Science 74:419-428.

[14]. Hameed A. 1975 Fertility investigations in the kole soils of Kerala. M.Sc (Agri) thesis, college of Agriculture Vellayani.

[15]. Holme, N.A and Mc Intyre, A.D. 1971. Methods for study of Marine Benthos, IBP Hand book No.6, Blackwell Scientific Publications.

[16]. Humphries P, Baldwin DS. 2003. Drought and aquatic ecosystems: an introduction. Freshwater Biology 48:11411146.

[17]. Jackson, M. L. 1973. Soil chemical analysis, Printers- Hall India Ltd, New Delhi.

[18]. Johnkutty, I. and Venugopal, V.K. 1993. Kole wetlands of Kerala, Kerala Agricultural University, Thrissur 68PP.

[19]. Lake PS, Bayly IAE, Morton DW. 1989. The phenology of a temporary pond in western Victoria, Australia, with special reference to invertebrate succession. Archiv für Hydrobiologie. 115:171-202.

[20]. Lancaster J, Hildrew AG. 1993. Flow refugia and the microdistribution of lotic macroinvertebrates. Journal of the North American Benthological Society 12:385-393.

[21]. Lobinske RJ, Ali A, Jack stout I. 1996. Quantitative and qualitative studied on chironomidae (Diptera) and selected physic chemical parameters in two tributaries of the Wekiva river, Central Florida. Florida Entomologist 79(4) pp.532-542.

[22]. Lytle DA, Poff NL. 2004. Adaptation to natural flow regimes. Trends in Ecology \& Evolution 19:94-100.

[23]. Margalef, R. 1968. Perspective in ecological theory. University of Chicago Press, Chicago: 111.

[24]. McIntyre, A.D. and Antasious Eleftheriou. 2005. 3rd edn. Methods for the study of Marine benthos. Blackwell Scientific Publications.

[25]. Millennium Ecosystem Assessment (MEA), 2005. Ecosystems and Human Well-being: Wetlands and Water Synthesis. World Resources Institute, Washington, DC.

[26]. Morse, C.J., Yang Lianfang and Tian Lixin (ed.). 1994. Aquatic Insects Of China Useful For Monitoring Water Quality. Hohai University Press, Nanjiing People's Republic of China pp 569.

[27]. Olsen, S., Cole, C., Watanabe, F. and Dean, L. 1954. Estimation of available phosphorus in soils by extraction with sodium bicarbonate. USDA Circular Nr 939, US Gov. Print. Office, Washington, D.C.

[28]. Pielou, E.C. 1966. Shannon's formula as a measurement of specific diversity and its use and misuse. American Naturalist, 100(914):463-465.

[29]. Real M, Rieradevall M, Prat N. 2000. Chironomus species (Diptera: Chironomidae) in the profundal benthos of Spanish reservoirs and lakes: Factors effecting distribution patterns. Freshwater Biology 43:1-18.

[30]. Reddy KR, DeLaune RD. 2008. Biogeochemistry of wetlands: science and applications CRC Press Taylor and Francis Group

[31]. Roger, P.A., Grant, I.F., Reddy, P.M. and Watanabe, I. 1987. The photosynthetic aquatic biomass in wetland rice fields and its effect on nitrogen dynamics. Efficiency of nitrogen fertilizers for rice. International Rice Research Institute, Los Banos, Philippines, 43-68 pp.

[32]. Salavert V, Zamora-Munoz C, Ruiz-Rodriguez M, Fernandez-Cortes A, Soler JJ. 2008. Climatic conditions, diapause and migration in a troglophile caddisfly. Freshwater Biology 989(53):1606-1617. 
[33]. Shannon, C.E. and Wiener, W. 1963. The Mathematical Theory of Communication. University of Illinois Press: Urbana $117 \mathrm{pp}$

[34]. Simpson, E, H. 1949. Measurement of diversity. Nature. 163:688.

[35]. Sivaperuman, C. and Jayson, E.A. 2000. Birds of Kole Wetlands, Thrissur, Kerala. Zoos' Print Journal, 15(10):344349.

[36]. Sommer B, Horwitz P. 2009. Macroinvertebrate cycles of decline and recovery in Swan Coastal Plain (Western Australia) wetlands affected by drought-induced acidification Hydrobiologia 624:191-203.

[37]. Stripari N. and Henry R., 2002. The invertebrate colonization during decomposition of Eichhornia azurea

[38]. Kunth in a lateral lake in the mouth zone of Paranapanema river into Jurumirim Reservoir (Sa o Paulo, Brazil). Braz. J. Biol., 62, 293-310.

[39]. Thomas J K. 2003. Muriyad wetlands: Ecological changes and human consequences. Project report submitted to Kerala Research Programme on Local Development, Centre for Developmental Studies, Thiruvanandapuram.

[40]. Thorp JH, Covich AP. 2001. Ecology and Classification of North American Freshwater Invertebrates. Academic Press, New York 1056 pp.

[41]. Vineetha S., Bijoy Nandan S., and Rakhi Gopalan K.P. 2015. Composition, abundance and diversity of macro benthic fauna in Kole paddy fields, Vembanad Kole wetland, India. International Journal of Current Research 07(10):2094120947.

[42]. Wiggins GB, Mackay RJ, Smith IM. 1980. Evolutionary and ecological strategies of animals in annual temporary pools. Archiv für Hydrobiologie, Supplement 58:97-206.

[43]. Williams DD. 1996. Environmental constraints in temporary freshwaters and their consequences for the insect fauna. Journal of the North American Benthological Society 16:634-650.

[44]. Williams DD. 2006. The Biology of Temporary Waters. Oxford: Oxford University Press 348 pp.

[45]. Yule, C.M. and Sen, Y.H. 2004. Freshwater invertebrates of the Malaysian region / editors Kuala Lumpur, Malaysia : Akademi Sains Malaysia. 